\title{
Product Development Considerations of Flaxseed Supplementation for the Aging Population: A Pilot Study
}

\author{
Jenny Y. Nguyen ${ }^{1}$, Cheryl R. Rock ${ }^{1}$, Virginia B. Gray ${ }^{1}$, Maria Claver $^{1} \&{\text { Christine } \text { Costa }^{2}}^{2}$ \\ ${ }^{1}$ Department of Family and Consumer Sciences, California State University, Long Beach, USA \\ ${ }^{2}$ School of Nursing, California State University, Long Beach, USA \\ Correspondence: Cheryl Rock, Department of Family and Consumer Sciences, California State University, Long \\ Beach, 1250 Bellflower Boulevard, Long Beach, CA 90840, USA. Tel: 1-562-985-4497. E-mail: \\ cheryl.rock@csulb.edu
}

Received: November 19, 2018 Accepted: December 7, $2018 \quad$ Online Published: April 2, 2019

doi:10.5539/jfr.v8n3p42 URL: https://doi.org/10.5539/jfr.v8n3p42

\begin{abstract}
Obesity, cardiovascular disease, and vulnerability among older adults highlight a critical need for a careful consideration of effective and preventive dietary interventions. Consuming flaxseed, along with a well-balanced diet, has been shown to significantly improve weight, waist circumference, blood pressure, serum lipids, plasma glucose levels, and inflammatory biomarkers. Although flaxseed exhibits anti-inflammatory and antioxidant properties, little is known regarding its consumer acceptability among older adults. The objective of this study was to investigate the acceptability of a bagel with $23 \%$ flaxseed in individuals 50 years and older using a 9-point Hedonic rating scale, Paired Preference test, and Food Action (FACT) rating scale. There were no significant differences between the control and flaxseed bagel in sensory attributes and FACT ratings in 20 participants $(69.0 \pm 6.3$ years old $)$. Age was significantly associated with the overall acceptability of the flaxseed bagel $(p=0.004)$. Appearance, color, flavor, and texture were strongly correlated $(p<0.01)$ to overall acceptability in both bagels. Further exploration of consumer acceptance of flaxseed products among older adults is needed; clinical trials may also shed light on potential health impacts of regular flax consumption.
\end{abstract}

Keywords: aging population, bagels, consumer acceptance, flaxseed

\section{Introduction}

Demographic changes in the United States have long indicated that it is an aging society. Between 2014 and 2060, the United States population is projected to increase from 319 million to 417 million, with 1 in 5 Americans expected to be 65 years old or over by 2030 and 1 in 4 expected to be 65 years old or over by 2060 (Colby \& Ortman, 2015). The baby boomer cohort, individuals born post-World War II between 1946 and 1964, is largely responsible for this growth in the older population as the first of this generation turned 65 in 2011(Colby \& Ortman, 2014). Consequently, this profound shift presents challenges to health care, nutrition services, and food supply systems for older individuals. An increase in longevity has been positively associated with chronic conditions that sometimes translate into functional disability and need for assistance (Buttorff, Ruder, \& Bauman, 2017).

Although illnesses and disease are common in older adults, no specific disease is inevitable in older age. Many diseases correlated with aging can be prevented, or at least delayed by greater awareness to health care strategies and maintenance. Interestingly, older individuals score higher in practicing health-promoting behaviors particularly in nutrition and health responsibility than any other age groups, suggesting that this population is eager to make lifestyle changes to preserve their health and freedom into advanced age in contrast to some who may not want to sacrifice taste and habits (Becker \& Arnold, 2004). Moreover, older consumers report that they regularly note the nutrition information on food labels when buying functional foods (Annunziata, Vecchio, \& Kraus, 2015). This suggests many older consumers are health-oriented, have an interest in eating foods that will preserve well-being, and may prefer consuming a food item with health benefits.

Flaxseed (Linum usitatissimum), accessible in many countries around the globe, has been drawing the attention of today's food industry due to its nutritive properties and versatility as a food ingredient. Flaxseed provides many nutrients, including omega $(\omega)-3$ polyunsaturated fatty acids (PUFAs, $28.7 \%$ ), lignans $(3.5 \%)$ including 
secoisolariciresinol diglucoside (SDG), and dietary fibers (27.3\%; U.S. Department of Agriculture, Agricultural Research Service, Nutrient Data Laboratory, 2016). Several human trials have shown that consuming $28-40 \mathrm{~g}$ of flaxseed daily, along with a well-balanced diet, has a significant improvement in health outcomes such as waist circumference, weight, blood pressure, serum lipids (total cholesterol, triglycerides, low density lipoprotein-cholesterol [LDL-C], very low density lipoprotein-cholesterol [VLDL-C], and high density lipoprotein-cholesterol [HDL-C] levels), plasma glucose levels, and inflammatory biomarkers (Caligiuri, Aukema, Ravandi, \& Pierce, 2014; Edel et al., 2015; Ricklefs-Johnson, Johnston, \& Sweazea, 2017; Saxena \& Katare, 2014; Torkan, Hassan Entezari, \& Siavash, 2015). Thus, incorporating flaxseed into the diet of older adults may provide a continuous preventive mechanism, which is cost effective compared to modern drug therapy.

Analyzing current dietary practices in to elucidate foods commonly consumed by the aging population can help direct product development of flaxseed-containing products. Carbohydrate intake of older adults showed an increase from $43 \%$ of total kilocalories (kcal) in 1977 to $49 \%$ of total kcal in 2010, which may be due to an increase in bread, grain, and dessert consumption as dominant calorie sources (Johnston, Poti, Popkin, \& Kenan, 2014). In a year-long study analyzing 12 daily choices of foods supplemented with $30 \mathrm{~g}$ milled flaxseed among older individuals, bagels were the popular choice to be ordered (37\%) compared to other food options with cinnamon raisin as most favorable compared to sunflower sesame and plain bagels; this suggests bagels as a possible candidate for fortification (Austria et al., 2016). Thus, enriching cinnamon raisin bagels with flaxseed that are regularly consumed by older adults might be beneficial to increase ALA, lignan, and dietary fiber intakes. However, there has been limited investigation on the consumer acceptability of flaxseed among older adults.

The overall goal of this study is to evaluate the acceptability of a flaxseed bagel among individuals 50 years and older. The specific objectives are to evaluate the degree of likability in sensory attributes (i.e., appearance, color, flavor, aroma, texture, and overall acceptability) utilizing the 9-point Hedonic rating scale, compare the preference for two bagels (control vs. flaxseed) using a Paired Preference test, and examine the acceptance of the bagel by measuring the frequency of the consumer desire to consume the bagel by applying the Food Action (FACT) rating scale.

\section{Method}

\subsection{Subject Characteristics and Sampling Procedure}

The pilot study was approved (1221541-2) by the Institutional Review Board. Subjects were then recruited, and the procedures were explained, and the consent form was read to and signed by each participant. Candidates were screened, and demographic data were collected using a questionnaire. Exclusion criteria included individuals who were $<50$ years old and were allergic to wheat. An honorarium in the form of a $\$ 5$ coffee gift card was awarded to participants who completed the sensory experiments.

\subsection{Bagel Formulation}

Clinical trials suggest consuming $30 \mathrm{~g}$ of flaxseed has positive health outcomes (de Oliveira et al., 2017; Saxena \& Katare, 2014; Torkan et al., 2015; Vuksan et al., 2017); therefore, a cinnamon raisin bagel with $30 \mathrm{~g}$ flaxseed (23\%) was created and evaluated against a control bagel (0\% flaxseed). Ingredients for the flaxseed and control bagel were obtained in the North American market (Table 1). Honey, active dry yeast, and water at a temperature between $38{ }^{\circ} \mathrm{C}$ to $43{ }^{\circ} \mathrm{C}$ were combined in a bowl. Bread flour, flaxseed mill, and salt were combined with the yeast mixture in a standing mixer for 10 minutes. Raisins and ground cinnamon were added to the dough until combined. The dough was formed into a ball, placed in a bowl, and loosely covered with plastic wrap until it doubled in size. The dough was divided into an average of $130 \mathrm{~g}$ portions and formed into a smooth ball. The center of the dough was pinched by hand to make a center hole of approximately 5 centimeter wide. The diameter of the bagel was roughly 10 centimeters. The formed bagels were placed onto a baking sheet lined with parchment paper and sprayed with oil and proofed for approximately 45 minutes, placed under the broiler at $260{ }^{\circ} \mathrm{C}$ for one minute on each side, and removed from the oven. Bagels were placed in boiling water at $100{ }^{\circ} \mathrm{C}$ for one minute on each side, removed from the water, and drained on a wire rack. Each bagel was placed on a baking tray lined with parchment paper sprayed with oil and baked in a convection oven for $30 \mathrm{~min}$ at $191{ }^{\circ} \mathrm{C}$. All samples were cooled, packaged in a sealed bag, and frozen immediately at $-18{ }^{\circ} \mathrm{C}$. The control bagels underwent the same process excluding the flaxseed as an ingredient. Bagels were thawed at room temperature (i.e., $23{ }^{\circ} \mathrm{C}$ ) 16 hours prior to sensory evaluation and cut into half and then quarters, with eight pieces from one bagel. One eighth of the flaxseed bagel and control bagel were placed in a 60-milliliter plastic portion cup separately and held for at least 1 hour before evaluation. 
Table 1. Formulation of bagels

\begin{tabular}{lll}
\hline Ingredients & Control & Flaxseed \\
\hline Organic flaxseed meal & $0.00 \mathrm{~g}$ & $30.00 \mathrm{~g}$ \\
& $(0.00 \%)$ & $(23.00 \%)$ \\
Unbleached bread flour & $72.37 \mathrm{~g}$ & $42.37 \mathrm{~g}$ \\
& $(55.49 \%)$ & $(32.49 \%)$ \\
Iodized salt & $1.22 \mathrm{~g}$ & $1.22 \mathrm{~g}$ \\
& $(0.94 \%)$ & $(0.94 \%)$ \\
Active dry yeast & $0.61 \mathrm{~g}$ & $0.61 \mathrm{~g}$ \\
& $(0.47 \%)$ & $(0.47 \%)$ \\
Organic honey & $3.02 \mathrm{~g}$ & $3.02 \mathrm{~g}$ \\
& $(2.32 \%)$ & $(2.32 \%)$ \\
Organic ground cinnamon & $0.74 \mathrm{~g}$ & $0.74 \mathrm{~g}$ \\
& $(0.57 \%)$ & $(0.57 \%)$ \\
Seedless raisin & $10.33 \mathrm{~g}$ & $10.33 \mathrm{~g}$ \\
& $(7.92 \%)$ & $(7.92 \%)$ \\
Water & $42.13 \mathrm{~g}$ & $42.13 \mathrm{~g}$ \\
& $(32.30 \%)$ & $(32.30 \%)$ \\
Total & $130.41 \mathrm{~g}$ & $130.41 \mathrm{~g}$ \\
\hline
\end{tabular}

\subsection{Sensory Evaluation}

Consumer tests were performed in a sensory evaluation laboratory. The assessment occurred under controlled conditions - a comfortable and quiet area without distractions (i.e., isolated booths) under fluorescent lighting and controlled temperature. During the sensory evaluation, panelists were provided with two coded food items in a random order, the flaxseed bagel (\#518) and the control bagel (\#496). Water was supplied to cleanse the palate between samples.

\subsection{Measures}

Bagels were assessed using the 9-point Hedonic scale, Paired Preference test, and the FACT rating scale. The 9-point hedonic scale is a tool that assesses a food item based on sensory attributes (i.e., appearance, color, flavor, texture, and overall acceptability; Girardot, Peryam, \& Shapiro, 1952). Score values included the following: $9=$ like extremely, $8=$ like very much, 7 = like moderately, $6=$ like slightly, $5=$ neither like nor dislike, $4=$ dislike slightly, 3 = dislike moderately, 2 = dislike very much, and $1=$ dislike extremely. The Paired Preference test established whether or not the flaxseed bagel was preferred over the control bagel (Thurstone, 1927). Each subject was requested to indicate the sample code they preferred the most. The FACT rating scale, a 9-point scale, measures consumer acceptance by having participants indicate the frequency of eating the food product (Schutz, 1965). The FACT scale values are as follows: $9=\mathrm{I}$ would eat this every opportunity that $\mathrm{I}$ had, $8=\mathrm{I}$ would eat this very often, $7=\mathrm{I}$ would frequently eat this, $6=\mathrm{I}$ like this and would eat it now and then, $5=\mathrm{I}$ would eat this if available but would not go out of my way, $4=\mathrm{I}$ do not like this but would eat this on an occasion, $3=\mathrm{I}$ would hardly ever eat this, 2 = I would eat this if there were no other food choices, and $1=\mathrm{I}$ would eat this only if forced.

\subsection{Statistical Analysis}

Statistical analysis was conducted utilizing the International Business Machine (IBM) Statistical Package for the Social Sciences (SPSS), Version 25. Descriptive statistics, frequencies, percentages, and variances were performed on demographics of survey participants as well as for all scorecard ratings. Prior to comparisons, skewness and kurtosis values were analyzed for normality. Paired samples $t$-tests were used to evaluate differences in means for sensory characteristics between the control and flaxseed bagels. Associations between demographic characteristics (gender and age group of panelists) and overall acceptability and FACT ratings for two food items were tested using chi-square $\left(\chi^{2}\right)$ test for independence analysis. Correlation coefficients between overall acceptability and other sensory attributes were calculated and reported. All analysis tests performed used a significance of $p<0.05$.

\section{Results}

\subsection{General Demographic Characteristics of the Study Population}

A total of 20 subjects, $25 \%$ male and $75 \%$ female, completed the sensory evaluation. The age of participants 
ranged from 54 to 76 years $(69.0 \pm 6.33)$. Age was normally distributed, with skewness of $-.975(S E=0.51)$ and kurtosis of $0.23(S E=0.99)$. Among these participants, $25 \%$ were $50-64$ years old, $55 \%$ were $65-74$ years old (young-old), and 20\% were 75-84 years old (old-old). Participants were all non-Hispanic whites (100\%).

\subsection{9-point Hedonic rating}

No significant differences were detected in sensory attributes including appearance (6.95 vs. 6.65$)$, color (7.00 vs. $6.55)$, flavor (6.75 vs. 5.90$)$, aroma (6.70 vs. 6.35$)$, texture (6.45 vs. 6.45$)$, and overall acceptability (7.00 vs. 6.05 ) for the control bagel compared to the flaxseed bagel, respectively (Table 2).

Table 2. Palatability factor, overall acceptability, and food action (FACT) rating of control bagels vs. bagels containing flaxseed $(n=20)$

\begin{tabular}{|c|c|c|c|}
\hline \multirow[b]{2}{*}{ Palatability factor } & Control & Flaxseed & \multirow[b]{2}{*}{$p$} \\
\hline & $M(S D)$ & $M(S D)$ & \\
\hline Appearance $^{\mathrm{a}}$ & $6.95(1.050)$ & $6.65(1.725)$ & 0.453 \\
\hline Color $^{\mathrm{a}}$ & $7.00(1.026)$ & $6.55(1.820)$ & 0.324 \\
\hline Flavor $^{\mathrm{a}}$ & $6.75(1.251)$ & $5.90(1.971)$ & 0.105 \\
\hline Aroma $^{a}$ & $6.70(1.525)$ & $6.35(1.981)$ & 0.439 \\
\hline Texture $^{\mathrm{a}}$ & $6.45(1.605)$ & $6.45(1.504)$ & 1.000 \\
\hline Overall acceptability $^{\mathrm{a}}$ & $7.00(1.026)$ & $6.05(2.038)$ & 0.078 \\
\hline FACT rating ${ }^{\mathrm{b}}$ & $5.20(1.281)$ & $4.90(2.075)$ & 0.527 \\
\hline
\end{tabular}

${ }^{\mathrm{a}}$ Measured on a scale from 1 to 9 , with $9=$ like extremely; $8=$ like very much; $7=$ like moderately; $6=$ like slightly; $5=$ neither like nor dislike; $4=$ dislike slightly; $3=$ dislike moderately; $2=$ dislike very much; $1=$ dislike extremely (Girardot et al., 1952).

${ }^{b}$ Measured on a scale from 1 to 9 , with $9=$ I would eat this every opportunity I had; $8=$ I would eat this very often; $7=\mathrm{I}$ would frequently eat this; $6=\mathrm{I}$ like this and would eat it now and then; $5=\mathrm{I}$ would eat this if available but would not go out of my way; $4=\mathrm{I}$ do not like this but would eat it on an occasion; $3=\mathrm{I}$ would hardly ever eat this; 2 = I would eat this if there were no other food choices; 1 = I would eat this only if forced (Schutz, 1965).

A $\chi^{2}$ test of independence was performed to examine the associations between demographic characteristics (i.e., gender and age group of panelists) and overall acceptability. The relationship between gender and overall acceptability and FACT ratings was not significant (Table 3). In contrast, there was a significant relationship between age group (50-64 years, young-old, and old-old) and overall acceptability of the flaxseed bagel ( $p=$ 0.004), while there was no association between age group and overall acceptability of the control bagel (Table 4).

Table 3. Relationship between gender of panelists and overall acceptability and food action (FACT) rating of bagels

\begin{tabular}{lllll}
\hline & & Male $(n=5)$ & Female $(n=15)$ & \\
\cline { 3 - 4 } & & $M(S D)$ & $M(S D)$ & $p$ \\
\hline Overall acceptability $^{\mathrm{a}}$ & Control & $7.20(0.837)$ & $6.93(1.100)$ & 0.848 \\
& Flaxseed & $5.80(1.095)$ & $6.13(2.295)$ & 0.121 \\
FACT rating $^{\mathrm{b}}$ & Control & $5.60(0.548)$ & $5.07(1.438)$ & 0.486 \\
& Flaxseed & $4.40(1.517)$ & $5.07(2.251)$ & 0.087 \\
\hline
\end{tabular}

${ }^{\text {a }}$ Measured on a scale from 1 to 9 , with $9=$ like extremely; $8=$ like very much; $7=$ like moderately; $6=$ like slightly; 5 = neither like nor dislike; $4=$ dislike slightly; $3=$ dislike moderately; $2=$ dislike very much; $1=$ dislike extremely (Girardot et al., 1952).

${ }^{\mathrm{b}}$ Measured on a scale from 1 to 9 , with $9=\mathrm{I}$ would eat this every opportunity I had; $8=\mathrm{I}$ would eat this very often; $7=\mathrm{I}$ would frequently eat this; $6=\mathrm{I}$ like this and would eat it now and then; $5=\mathrm{I}$ would eat this if available but would not go out of my way; $4=\mathrm{I}$ do not like this but would eat it on an occasion; $3=\mathrm{I}$ would hardly ever eat this; 2 = I would eat this if there were no other food choices; 1 = I would eat this only if forced (Schutz, 1965). 
Table 4. Relationship between age group of panelists and overall acceptability and food action (FACT) rating of bagels

\begin{tabular}{llllll}
\hline & & $50-64$ years $(n=5)$ & $65-74$ years $(n=11)$ & $75-84$ years $(n=4)$ & \\
\cline { 3 - 5 } & & $M(S D)$ & $M(S D)$ & $M(S D)$ & $p$ \\
\hline Overall acceptability $^{\mathrm{a}}$ & Control & $7.00(0.707)$ & $7.00(1.183)$ & $7.00(1.155)$ & 0.132 \\
& Flaxseed & $6.40(2.510)$ & $6.00(1.612)$ & $5.75(2.986)$ & 0.004 \\
FACT rating $^{\mathrm{b}}$ & Control & $5.20(0.447)$ & $5.45(1.508)$ & $4.50(1.291)$ & 0.078 \\
& Flaxseed & $5.20(2.490)$ & $5.00(2.049)$ & $4.25(2.062)$ & 0.089 \\
\hline
\end{tabular}

${ }^{a}$ Measured on a scale from 1 to 9 , with $9=$ like extremely; $8=$ like very much; $7=$ like moderately; $6=$ like slightly; 5 = neither like nor dislike; $4=$ dislike slightly; $3=$ dislike moderately; $2=$ dislike very much; $1=$ dislike extremely (Girardot et al., 1952).

${ }^{\mathrm{b}}$ Measured on a scale from 1 to 9 , with $9=\mathrm{I}$ would eat this every opportunity I had; $8=\mathrm{I}$ would eat this very often; 7 = I would frequently eat this; $6=\mathrm{I}$ like this and would eat it now and then; $5=\mathrm{I}$ would eat this if available but would not go out of my way; $4=\mathrm{I}$ do not like this but would eat it on an occasion; $3=\mathrm{I}$ would hardly ever eat this; 2 = I would eat this if there were no other food choices; 1 = I would eat this only if forced (Schutz, 1965).

Table 5 showed that for the control bagel, flavor was strongly correlated $(r=0.907, p<0.01)$ to overall acceptability, which was followed by texture $(r=0.787, p<0.01)$, appearance $(r=0.778, p<0.01)$, and color $(r$ $=0.704, p<0.01)$. Aroma was moderately associated with overall acceptability for the control bagel $(r=0.599$, $p<0.01)$. For the flaxseed bagel, appearance was most strongly correlated $(r=0.785, p<0.01)$ with overall acceptability, which was followed by flavor $(r=0.758, p<0.01)$, color $(r=0.754, p<0.01)$, and texture $(r=$ $0.749, p<0.01)$. In addition, overall acceptability and frequency of eating were strongly correlated $(r=0.887, p$ $<0.01$ ) for the flaxseed bagel.

Table 5. Correlation of sensory attributes and food action (FACT) rating to overall acceptability of bagels

\begin{tabular}{lcc}
\hline Sensory attributes & \multicolumn{2}{c}{ Overall acceptability } \\
\cline { 2 - 3 } & Control & Flaxseed \\
\hline Appearance & $0.778^{* *}$ & $0.785^{* *}$ \\
Color & $0.704^{* *}$ & $0.754^{* *}$ \\
Flavor & $0.907^{* *}$ & $0.758^{* *}$ \\
Aroma & $0.599^{* *}$ & 0.413 \\
Texture & $0.787^{* *}$ & $0.749^{* *}$ \\
FACT rating & $0.761^{* *}$ & $0.887^{* *}$ \\
\hline
\end{tabular}

** Correlation is significant at the 0.01 level (2-tailed).

* Correlation is significant at the 0.05 level (2-tailed).

\subsection{Paired Preference test}

Half (50\%) of the participants preferred the flaxseed bagel while the other half (50\%) preferred the control bagel.

\subsection{FACT rating}

There was no difference in how often the participants would be willing to eat the control bagel $(5.20 \pm 1.28$, I would eat this if available but would not go out of my way) compared to the flaxseed bagel $(4.90 \pm 2.08$, I do not like this but would eat it on an occasion), displayed in Table 3. Among participants, 25\% rated flaxseed bagels as "I like this and would eat it now and then," followed by "I would frequently eat this" (20\%), and "I would eat this if there were no other food choices" (15\%). There was no significant relationship between demographic characteristics (gender and age group) and FACT ratings in two bagels (Table 3).

\section{Discussion}

The present findings demonstrate that milled flaxseed can be successfully incorporated into a cinnamon raisin bagel as there were no significant differences in sensory attributes between the two bagels, overall acceptability, preference, and FACT ratings. These results are in disagreement with Ramcharitar, Badrie, Mattfeldt-Beman, Matsuo, and Ridley (2005) that concluded there were significant differences in sensory attributes, overall acceptability, and FACT ratings between a control muffin and a flaxseed muffin among individuals from all ages. 
However, the same study (Ramcharitar et al., 2005), as well as findings from Aliani, Ryland, and Pierce (2012) suggest that consumer acceptance of flaxseed bagels was higher among older adults when compared to younger adults. This supports the overall findings of this study, as the mean sensory attributes for the flaxseed bagel were between 5.90 (neither like nor dislike) and 6.65 (like slightly), which was deemed to be acceptable. The gender of the panelists had no relationship with overall acceptability or FACT ratings of the control vs. flaxseed bagel; this finding aligns with results from studies evaluating the acceptability of flaxseed muffins and bagels among individuals from all ages (Aliani et al., 2012; Ramcharitar et al., 2005).

Findings also demonstrated that there was a significant relationship between age group $(50-64,65-74$, and 75-84 years old) and overall acceptability of flaxseed bagels. Mean values for overall acceptability were lower for those in the 75-84 years old individuals (neither like nor dislike) when compared to individuals age 50-74 years (like slightly), which aligns with the results of a study that showed higher mean values for overall acceptability in flaxseed bagels for individuals ages 35-64 years (like slightly) when compared to younger individuals (16-34 years, neither like nor dislike; Aliani et al., 2012). This may suggest that segments within the aging population have a different acceptance of flaxseed. For example, factors, such as physiological variables (i.e., chewing efficiency, taste, olfactory, and trigeminal stimuli), life-courses (i.e., experiences encountered during a lifetime), socioeconomic situation, and other social and psychological variables may influence preferences and consequently food choices of older adults (Doets \& Kremer, 2016; Kamphuis, de Bekker-Grob, \& van Lenthe, 2015; van der Zanden, van Kleef, de Wijk, \& van Trijp, 2014).

The hedonic test results suggest that appearance was most strongly correlated to overall acceptability, which was followed by flavor, color, and texture for the flaxseed bagel. This has implications for guiding product developers toward appropriate strategies that will enhance the appearance, flavor, color, and texture to improve consumer acceptability for bagels among older adults. It was also found that overall acceptability and frequency of eating were strongly correlated, which aligns with results of a similar study among 89 untrained panelists (Ramcharitar et al., 2005). This confirms that the FACT rating scale can be considered another measure of acceptability; the more the bagel is liked, the more likely it is to be consumed more often, leading to increase demand. To achieve better sensory acceptance scores, different flavored bagels should be considered for future sensory evaluations as blueberry flavored bagels were rated most eaten compared to other flavors (Aliani et al., 2012).

\subsection{Limitations}

Although literature deemed the sample size adequate for a pilot food product sensory evaluation, results are unlikely to be representative of the population of older adults. Findings should be tested in different geographical locations since consumer preferences may vary significantly in different cultural contexts. In addition, freezing of samples may have affected the appearance, color, flavor, aroma, texture, and overall acceptability of the bagels; therefore, it may be suggested to explore other storage options.

\section{Conclusion}

Our study provides promising avenues for future research. While there were no significant differences in sensory attributes and intended frequency of eating in both bagels, product developers may consider improving appearance, flavor, color, and texture of a food product supplemented with flaxseed to increase overall acceptance and intended frequency of eating the product. Future experiments should additionally analyze other flavored bagels (i.e., blueberry bagels) as a promising alternative for fortification with flaxseed for use in sensory evaluations among different segments of the older population.

\section{References}

Aliani, M., Ryland, D., \& Pierce, G. N. (2012). Effect of flax addition on the flavor profile and acceptability of bagels. Journal of Food Science, 71(1), S62-S70. https://doi.org/10.1111/j.1750-3841.2011.02509.x

Annunziata, A., Vecchio, R., \& Kraus, A. (2015). Awareness and preference for functional foods: The perspective of older Italian consumers. International Journal of Consumer Studies, 39(4), 352-361. https://doi.org/10.1111/ijcs.12202

Austria, J. A., Aliani, M., Malcolmson, L. J., Dibrov, E., Blackwood, D. P., Maddaford, T. G., ... Pierce, G. N. (2016). Daily choices of functional foods supplemented with milled flaxseed by a patient population over one year. Journal of Functional Foods, 26, 772-780. https://doi.org/10.1016/j.jff.2016.08.045

Becker, C. M., \& Arnold, W. (2004). Health promoting behaviors of older Americans versus young and middle aged adults. Educational Gerontology, 30(10), 835-844. https://doi.org/10.1080/03601270490507277 
Buttorff, C., Ruder, T., \& Bauman, M. (2017). Multiple chronic conditions in the United States. Santa Monica, CA: RAND Corporation. Retrieved from https://www.rand.org/content/dam/rand/pubs/tools/TL200/TL221/RAND_TL221.pdf

Caligiuri, S. P. B., Aukema, H. M., Ravandi, A., \& Pierce, G. N. (2014). Elevated levels of pro-inflammatory oxylipins in older subjects are normalized by flaxseed consumption. Experimental Gerontology, 59, 51-57. https://doi.org/10.1016/j.exger.2014.04.005

Colby, S. L., \& Ortman, J. M. (2014). The baby boom cohort in the United States: 2012 to 2060 (Current Population Reports No. P25-1141). Washington, DC: U.S. Census Bureau. Retrieved from http://www.census.gov/content/dam/Census/library/publications/2014/demo/p25-1141.pdf

Colby, S. L., \& Ortman, J. M. (2015). Projections of the size and composition of the U.S. population: 2014 to 2060 (Current Population Reports No. P25-1143). Washington, DC: U.S. Census Bureau. Retrieved from https://www.census.gov/content/dam/Census/library/publications/2015/demo/p25-1143.pdf

de Oliveira, P. A., Kovacs, C., Moreira, P., Magnoni, D., Saleh, M. H., \& Faintuch, J. (2017). Unsaturated fatty acids improve atherosclerosis markers in obese and overweight non-diabetic elderly patients. Obesity Surgery, 27(10), 2663-2671. https://doi.org/10.1007/s11695-017-2704-8

Doets, E. L., \& Kremer, S. (2016). The silver sensory experience - A review of senior consumers' food perception, liking and intake. Food Quality and Preference, 48, 316-332. https://doi.org/10.1016/j.foodqual.2015.08.010

Edel, A. L., Rodriguez-Leyva, D., Maddaford, T. G., Caligiuri, S. P., Austria, J. A., Weighell, W., ... Pierce, G. N. (2015). Dietary flaxseed independently lowers circulating cholesterol and lowers it beyond the effects of cholesterol-lowering medications alone in patients with peripheral artery disease. The Journal of Nutrition, 145(4), 749-757. https://doi.org/10.3945/jn.114.204594

Girardot, N. F., Peryam, D. R., \& Shapiro, R. (1952). Selection of sensory testing panels. Food Technology, 4, 140-143.

Johnston, R., Poti, J. M., Popkin, B. M., \& Kenan, W. R. (2014). Eating and aging: Trends in dietary intake among older Americans from 1977-2010. Journal of Nutrition, Health \& Aging, 18(3), 234-242. https://doi.org/10.1007/s12603-013-0387-y

Kamphuis, C. B., de Bekker-Grob, E. W., \& van Lenthe, F. J. (2015). Factors affecting food choices of older adults from high and low socioeconomic groups: A discrete choice experiment. American Journal of Clinical Nutrition, 101(4), 768-774. https://doi.org/10.3945/ajcn.114.096776

Ramcharitar, A., Badrie, N., Mattfeldt-Beman, M., Matsuo, H., \& Ridley, C. (2005). Consumer Acceptability of Muffins with Flaxseed (Linum usitatissimum). Journal of Food Science, 70(7), s504-s507. https://doi.org/10.1111/j.1365-2621.2005.tb11499.x

Ricklefs-Johnson, K., Johnston, C. S., \& Sweazea, K. L. (2017). Ground flaxseed increased nitric oxide levels in adults with type 2 diabetes: A randomized comparative effectiveness study of supplemental flaxseed and psyllium fiber. Obesity Medicine, 5, 16-24. https://doi.org/10.1016/j.obmed.2017.01.002

Saxena, S., \& Katare, C. (2014). Evaluation of flaxseed formulation as a potential therapeutic agent in mitigation of dyslipidemia. Biomedical Journal, 37(6), 386-390. https://doi.org/10.4103/2319-4170.126447

Schutz, H. G. (1965). Food Action rating scale for measuring food acceptance. Journal of Food Science, 30(2), 365-374. https://doi.org/10.1111/j.1365-2621.1965.tb00316.x

Thurstone, L. L. (1927). A law of comparative judgment. Psychological Review, 34(4), 273-286.

Torkan, M., Hassan Entezari, M., \& Siavash, M. (2015). Effect of flaxseed on blood lipid level in hyperlipidemic patients. Reviews on Recent Clinical Trials, 10, 61-67. https://doi.org/10.2174/1574887110666150121154334

U.S. Department of Agriculture, Agricultural Research Service, Nutrient Data Laboratory. (2016). USDA Branded Food Products Database. Retrieved from https://ndb.nal.usda.gov/

van der Zanden, L. D. T., van Kleef, E., de Wijk, R. A., \& van Trijp, H. C. M. (2014). Understanding heterogeneity among elderly consumers: An evaluation of segmentation approaches in the functional food market. Nutrition Research Reviews, 27, 159-171. https://doi.org/10.1017/S0954422414000092

Vuksan, V., Choleva, L., Jovanovski, E., Jenkins, A. L., Au-Yeung, F., Dias, A. G., ... Duvnjak, L. (2017). 
Comparison of flax (Linum usitatissimum) and Salba-chia (Salvia hispanica L.) seeds on postprandial glycemia and satiety in healthy individuals: A randomized, controlled, crossover study. European Journal of Clinical Nutrition, 71(2), 234. https://doi.org/10.1038/ejcn.2016.148

\section{Copyrights}

Copyright for this article is retained by the author(s), with first publication rights granted to the journal.

This is an open-access article distributed under the terms and conditions of the Creative Commons Attribution license (http://creativecommons.org/licenses/by/4.0/). 